\title{
Chromogranin A Expression in Normal and Malignant Human Tissues
}

\author{
Lee J. Helman, Adi F. Gazdar, Jae-Gahb Park, Pamela S. Cohen, James D. Cotelingam, and Mark A. Israel
}

Pediatric Branch, Naval Medical Oncology Branch, National Cancer Institute, Bethesda, Maryland 20892;

and Department of Pathology, Bethesda Naval Hospital, Bethesda, Maryland 20814

\begin{abstract}
We used a recombinant cDNA probe for human chromogranin A to measure the expression of mRNA encoded by this gene in a variety of normal human tissues and tumor specimens using Northern blot and in situ hybridization analysis. With few exceptions, the expression of chromogranin A mRNA appears to be restricted to normal tissues and tumors of neuroendocrine lineage. However, we have detected mRNA expression of this gene in 1 of 14 cell lines and 2 of 13 tumor specimens of colon adenocarcinoma. The finding of chromogranin $A$ expression in some colon carcinomas suggests that a previously unrecognized subgroup of these tumors has neuroendocrine features. The detection of this subgroup demonstrates the potential for improving tumor classification through the use of techniques and reagents developed by recombinant DNA technology.
\end{abstract}

\section{Introduction}

Molecular genetics affords the opportunity to examine tissue specimens in a uniquely specific manner at the level of either gene structure or RNA expression. Furthermore, such evaluations do not require either an antibody or a functional assay for the protein product of the gene that is being studied. The ability to examine human tumors in this manner may both permit the subclassification of tumors into increasingly specific disease entities as well as give insight into the molecular mechanisms underlying tumorigenesis. We sought to evaluate the application of molecular analysis to tumor classification by examining various tissues for the expression of chromogranin A (cga), ${ }^{1}$ a marker for tissues with neuroendocrine features. To measure cga RNA expression in normal and malignant human tissues, we used a molecular probe that recognizes the mRNA that encodes cga in Northern blot and in situ hybridization analyses.

Cga was originally isolated as the major secretory protein of adrenal medulla chromaffin granules and accounts for about one half of the soluble protein content within the granules (1). While the precise function of cga is unknown, recent data suggest that it may play a critical role in the maturation of secretory granules (2). In addition, the expression of this protein appears to be developmentally regulated in human chromaffin tissue with levels being first detected at $8 \mathrm{wk}$ of gesta-

Address all correspondence to Dr. Helman, Pediatric Branch, National Cancer Institute, Building 10, Room 13N240, Bethesda, MD 20892.

Received for publication 13 August 1987 and in revised form 1 March 1988.

1. Abbreviations used in this paper: cga, chromogranin A.

The Journal of Clinical Investigation, Inc.

Volume 82, August 1988, 686-690 tion and progressive increases during the first year of life (unpublished observations). Immunoreactivity of this $71-\mathrm{kD}$ acidic protein has now been extensively characterized and shown to be specifically present in normal and malignant cells of the diffuse neuroendocrine system (3-8). $81 \%$ of patients with neuroendocrine tumors have an elevation in serum cga levels, and serum cga is now used as a marker for neuroendocrine tumors (8). In addition, an elevation in serum cga levels may be a useful marker for small cell lung carcinoma disease activity (9). In this study, we have used nucleic acid hybridization analysis to characterize the expression of cga in a variety of human tissues and we have identified a number of adenocarcinomas of the colon that unexpectedly express cga.

\section{Methods}

Northern blot analysis. Total RNA was extracted from human tissues and cell lines using guanidine thiocyanate (10), and RNA concentration was determined by ultraviolet spectroscopy at $260 \mathrm{~nm}$. Northern blot analysis was performed as previously described (11). Briefly, $10-30 \mu \mathrm{g}$ of total RNA was size fractionated on $1 \%$ agarose/formaldehyde gels. The positions of the $28 \mathrm{~S}$ and $18 \mathrm{~S}$ ribosomal RNA were determined by ultraviolet irradiation of ethidium bromide stained gels, and the RNA was then transferred to Nytran (Schleicher \& Schuell Inc., Keene, NH). The membrane was hybridized according to the manufacturer's recommendations. To confirm that all lanes contained intact RNA at the expected concentration, the blots were stripped in $50 \%$ formamide $/ 1 \times$ standard saline citrate (SSC) $(1 \times$ SSC $=0.15 \mathrm{M}$ sodium chloride/ $0.015 \mathrm{M}$ sodium citrate) and rehybridized to an in vitro isotopically labeled actin probe (12) (data not shown).

In situ hybridization studies. In situ hybridization was performed as previously described $(13,14)$ with the following modifications. Cultured cells or adrenal tissue sections ( $8 \mu \mathrm{m}$ diam) were placed on polylysine-coated silanated slides, which were activated by treatment with $2.5 \%$ glutaraldehyde and $0.1 \mathrm{M}$ sodium periodate (15). After fixation with periodate-lysine-paraformaldehyde-glutaraldehyde and digestion with $0.2 \mathrm{~N} \mathrm{HCl}$ and $10 \mu \mathrm{g} / \mathrm{ml}$ proteinase $\mathrm{K}$, samples were acetylated as previously described (16), and prehybridized in $50 \%$ formamide, $2 \times$ SSC, $50 \mathrm{mM}$ Tris pH 7.4, $1 \mathrm{mM}$ EDTA, $0.02 \%$ Ficoll, $0.02 \%$ polyvinylpyrrolidone, $1 \mathrm{mg} / \mathrm{ml} \mathrm{BSA}$, and $33 \mu \mathrm{g} / \mathrm{ml}$ yeast tRNA at $65^{\circ} \mathrm{C}$ for $3 \mathrm{~h}$. Samples were hybridized at $65^{\circ} \mathrm{C}$ for $16 \mathrm{~h}$ in $12 \mu \mathrm{l}$ reaction mixtures containing $50 \%$ formamide, $10 \%$ dextran, $50 \mathrm{mM}$ Tris pH 7.4, 1 mM EDTA, $1 \times$ Denhardt's, $10 \mathrm{nM} \mathrm{DTT,} 500 \mu \mathrm{g} / \mathrm{ml}$ yeast tRNA, $500 \mu \mathrm{g} / \mathrm{ml}$ sheared salmon sperm DNA and $5 \times 10^{5} \mathrm{cpm}$ ${ }^{35}$ S-labeled cga RNA. Slides were washed once briefly in $2 \times$ SSC at $20^{\circ} \mathrm{C}$, once in $50 \%$ formamide, $2 \times \mathrm{SSC}$ at $20^{\circ} \mathrm{C}$ for $15 \mathrm{~min}$, three times in $2 \times \mathrm{SSC}, 0.1 \% \mathrm{SDS}$ at $65^{\circ} \mathrm{C}$ for $15 \mathrm{~min}$, and once at $37^{\circ} \mathrm{C}$ in $0.3 \mathrm{M}$ $\mathrm{NaCl}, 10 \mathrm{mM}$ Tris pH 7.4 containing $40 \mu \mathrm{g} / \mathrm{ml} \mathrm{RNase} \mathrm{A} \mathrm{and} 5 \mu \mathrm{g} / \mathrm{ml}$ RNase T1. These washes were followed by $15 \mathrm{~min}$ washes first in $2 \times$ SSC and $0.1 \times$ SDS, and then in $0.1 \times$ SSC and, $0.1 \%$ SDS at $65^{\circ} \mathrm{C}$. Slides were then dehydrated through graded alcohols. Autoradiography was performed as previously described $(13,14)$, and slides were stained with hematoxylin and eosin by standard techniques.

Probes. A 2.1-kb Pst I fragment containing the entire coding sequence for human cga cloned into pUC9, pHCGA, was used in Northern blot hybridizations (Helman, L. J., T. G. Ahn, M. A. Levine, 
A. Allison, P. S. Cohen, M. J. Cooper, D. V. Cohn, and M. A. Israel, manuscript submitted for publication). The plasmid was in vitro labeled with DNA polymerase using $\left[{ }^{32} \mathrm{P}\right] \mathrm{dCTP}$ to a specific activity of $>1 \times 10^{8} \mathrm{cpm} / \mu \mathrm{g}$.

A Hind III/Eco RI fragment of pHCGA containing the entire 2.1kb Pst I fragment was subcloned into $p$ GEM3 (Promega Biotec, Madison, WI). RNA was prepared using T7 polymerase according to the manufacturer's recommendations (Promega Biotec) using a Pvu II-digested template yielding a $500 \mathrm{bp}$ RNA fragment that was labeled with ${ }^{35} \mathrm{~S}-\mathrm{UTP}$ to a specific activity of $10^{9} \mathrm{cpm} / \mu \mathrm{g}$ and then it was used as a molecular probe for in situ hybridization.

\section{Results}

Distribution of cga expression in normal and malignant human tissue and cell lines. To demonstrate the specificity of hybridization analysis for the characterization of cga expression in neuroendocrine cells, we examined the pattern of cga expression in human adrenal glands using in situ hybridization. As shown in Fig. 1, a hybridization signal identifying the presence of cga mRNA is found exclusively in the neuroendocrine adrenal medulla and not in the endocrine adrenal cortex. A of this figure shows a bright field examination in which the hybridization signal appears as dark grains that are readily visible only at higher magnification (see below). B shows the identical section of adrenal gland in dark field, which demonstrates the hybridization of the cDNA probe to the central adrenal medulla while the surrounding cortex shows no hybridization. $\mathrm{C}$ shows a close-up bright field of the framed area from $A$ in which the junction between the adrenal cortex and the central adrenal medulla is shown to demonstrate the speci- ficity of hybridization to adrenal medullary cells. A Northern blot analysis of adrenal gland tissues (Fig. 2) confirms this pattern of reactivity, which demonstrates the presence of cga mRNA in the adrenal medulla but not in the adrenal cortex.

Northern blot analysis of tumor specimens for cga expression demonstrates the presence of the $2.1-\mathrm{kb}$ chromogranin message in representative neuroendocrine tumors (Fig. 3, lanes $3,7,8$, and 13) but not in carcinomas, sarcomas, and lymphoid tumors (Fig. 3, lanes 1, 2, 4-6, 9-12). Tables I and II summarize our Northern blot evaluation of cga expression in 111 human tissues and demonstrates that expression of this gene can be detected in normal neuroendocrine tissues and neuroendocrine tumors but not in normal nonneuroendocrine tissues or most nonneuroendocrine tumors. The experiments reported in Table II indicate that the expression of cga message in cell lines is concordant with the pattern of expression seen in fresh normal tissues and tumor specimens. Each human neuroendocrine tumor cell line examined expressed high levels of cga. With a single exception, tumor cell lines from sarcomas, carcinomas, lymphomas, and gliomas do not express detectable levels of this gene.

The observation of cga expression in this exception, a colon carcinoma cell line, complements the data in Table 1, which indicates that 2 out of 13 colon adenocarcinoma tumor specimens also express cga. Fig. $4 A$ shows a Northern blot that demonstrates the $2.1-\mathrm{kb}$ cga mRNA in a colon adenocarcinoma tumor specimen (lane 7). While the level of expression in the tumor is clearly less than the level of expression seen in a pheochromocytoma tumor specimen (lane 1 ), it is easily distinguishable from the six other colon adenocarcinomas exam-
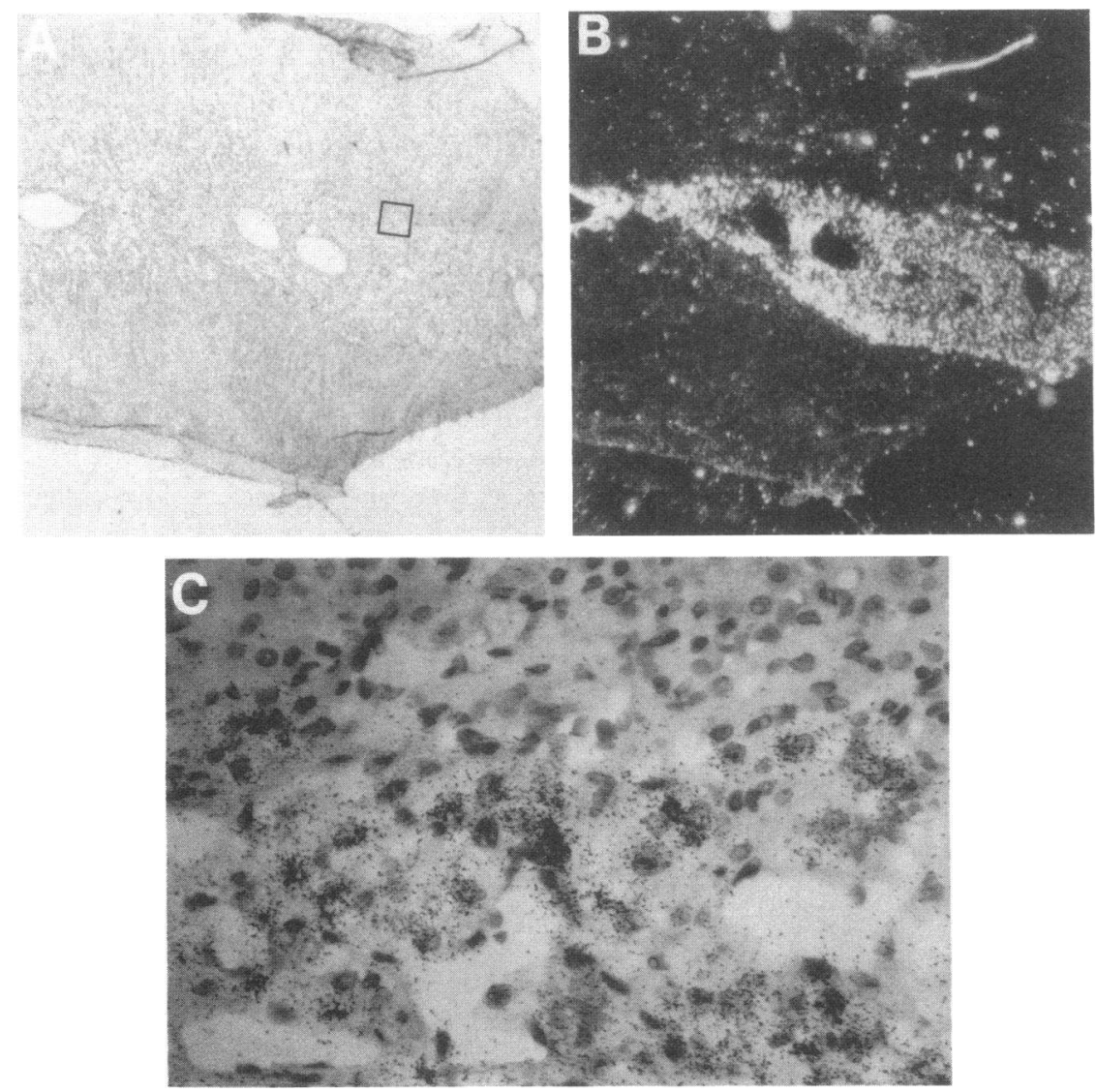

Figure 1. In situ hybridization analysis of cga expression in human adrenal gland. A section of a human adrenal gland was prepared as described and hybridized to a human cga RNA antisense probe. $(A)$ A brightfield exposure that shows hybridization (dark grains) over the central medullary portion of the gland and no hybridization over the surrounding cortex. $(B)$ A darkfield exposure of the identical section to highlight the pattern of hybridization (light grains) specifically to the adrenal medulla. $(C)$ A close-up of the boxed area of A which contains the medullary-cortical junction. 


\section{6}

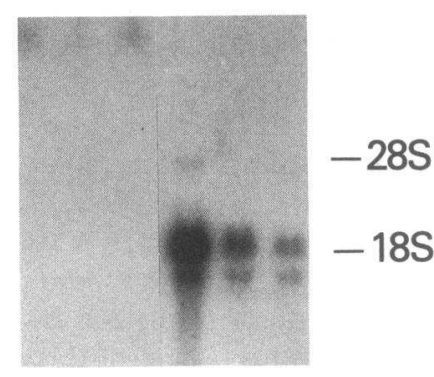

Figure 2. Northern blot analysis of cga expression in human adrenal medulla and adrenal cortex. $10 \mu \mathrm{g}$ of total RNA extracted from adrenal cortex (lanes $1-3$ ) or adrenal medulla (lanes 4-6) was hybridized to ${ }^{32}$ P-labeled pHCGA using standard Northern blotting procedures as described in Methods. Expression of the 2.1-kb cga mRNA is readily detectable in the medullae,

while no expression of this message is detectable in the cortices. We believe the differences in signal intensity between the three adrenal medullae examined here are due to contamination of the samples by varying amounts of adrenal cortical tissue that could not be completely removed from these clinical specimens before RNA extraction.

ined in this experiment (lanes 2-6). The Northern blot shown in Fig. $4 B$ indicates that the authentic $2.1-\mathrm{kb}$ cga mRNA is readily detectable in $10 \mu \mathrm{g}$ of total RNA derived from a colon adenocarcinoma cell line H716 (17) (lane 4), which indicates a relatively high level of expression in this cell line. To determine whether the cga expression in $\mathrm{H} 716$ was uniform or whether this expression was heterogeneous among the tumor cells, we examined a cytospin preparation of this cell line by in situ hybridization. Fig. 5 shows such an analysis and demonstrates that all the cells appear to be expressing cga.

\section{Discussion}

Our analysis of normal and malignant tissues for the expression of cga RNA confirms the utility of our recombinant DNA probe pHCGA for the detection of neuroendocrine features in human tissues. The expression of cga was detected in every neuroendocrine tissue examined. With the exception of colon adenocarcinoma, nonneuroendocrine tissues did not express cga.

Using this recombinant DNA probe for cga, we have demonstrated that 2 of 13 adenocarcinomas of the colon and 1 of 14 cell lines derived from adenocarcinomas of the colon express this neuroendocrine specific gene. The colon adenocarcinomas that express cga are indistinguishable from all other

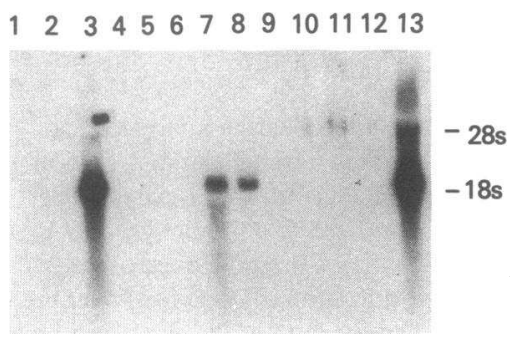

Figure 3. Northern blot analysis of cga expression in human tumors. $10 \mu \mathrm{g}$ of total RNA was extracted from various tumor specimens as described and analyzed for expression of cga by Northern blotting using ${ }^{32}$ P-labeled, pHCGA.

Lane 1, adrenocortical carcinoma; lane 2, renal cell carcinoma; lane 3. Merkel cell tumor; lane 4, thymoma; lane 5, osteosarcoma; lane 6, breast adenocarcinoma; lane 7, carotid body tumor; lane 8 , bronchial carcinoid; lane 9, multiple myeloma; lane 10, breast adenocarcinoma; lane 11, renal cell carcinoma; lane 12, mycosis fungoides; lane 13 , pheochromocytoma.
Table I. Expression of CGA in Normal and Neoplastic Human Tissues

\begin{tabular}{|c|c|}
\hline Tissue type & No. positive/No. tested \\
\hline \multicolumn{2}{|l|}{ Normal human tissues } \\
\hline Colon & $0 / 2$ \\
\hline Spleen & $0 / 3$ \\
\hline Muscle & $0 / 3$ \\
\hline Kidney & $0 / 3$ \\
\hline Pancreas & $0 / 1$ \\
\hline Brain (cortex) & $0 / 2$ \\
\hline Thyroid & $0 / 1$ \\
\hline Adrenal cortex & $0 / 6$ \\
\hline Adrenal medulla & $4 / 4$ \\
\hline Anterior pituitary & $1 / 1$ \\
\hline \multicolumn{2}{|l|}{ Neoplastic neuroendocrine tissue } \\
\hline Medullary thyroid carcinoma & $9 / 10$ \\
\hline Pheochromocytoma & $10 / 10$ \\
\hline Carcinoid tumor & $3 / 3$ \\
\hline Islet cell tumor & $3 / 4$ \\
\hline Parathyroid adenoma & $3 / 4$ \\
\hline Merkel cell tumor & $1 / 1$ \\
\hline Carotid body tumor & $1 / 1$ \\
\hline Small cell lung cancer & $2 / 3$ \\
\hline \multicolumn{2}{|c|}{ Neoplastic nonneuroendocrine tissue } \\
\hline Breast carcinoma & $0 / 13$ \\
\hline Adrenocortical carcinoma & $0 / 3$ \\
\hline Renal cell carcinoma & $0 / 9$ \\
\hline Lymphoid tumors & $0 / 4$ \\
\hline Thymoma & $0 / 2$ \\
\hline Sarcoma (mixed) & $0 / 3$ \\
\hline Thyroid carcinoma & $0 / 1$ \\
\hline Pancreatic carcinoma & $0 / 2$ \\
\hline Colon adenocarcinoma & $2 / 13$ \\
\hline
\end{tabular}

10-20 $\mu \mathrm{g}$ of total RNA extracted from the tissues listed in Table I was size fractionated on an agarose-formaldehyde gel, transferred to nylon membrane, and analyzed for expression of cga by hybridization to ${ }^{32} \mathrm{P}$-labeled pHCGA. Autoradiographs were exposed for $1-7 \mathrm{~d}$ with intensifying screens. Numbers in the denominator indicate total number of tissues analyzed, and numbers in the numerator indicate the number of tissues that expressed cga.

Table II. Expression of cga in Human Tumor Cell Lines

\begin{tabular}{lc}
\hline \multicolumn{1}{c}{ Tissue type } & No. positive/No. tested \\
\hline Neuroendocrine & \\
Medullary thyroid carcinoma & $1 / 1$ \\
Carcinoid & $1 / 1$ \\
Small cell lung cancer & $5 / 5$ \\
Nonneuroendocrine & \\
Breast & $0 / 2$ \\
Lymphoid & $0 / 2$ \\
Sarcoma (Ewing's) & $0 / 2$ \\
Glioma & $0 / 10$ \\
Colon adenocarcinoma & $1 / 14$
\end{tabular}

Expression of cga in human tumor cell lines. $10 \mu \mathrm{g}$ of total RNA from the human tumor cell lines listed was analyzed for expression of cga as described in Table I. Numbers are expressed as in Table I. 

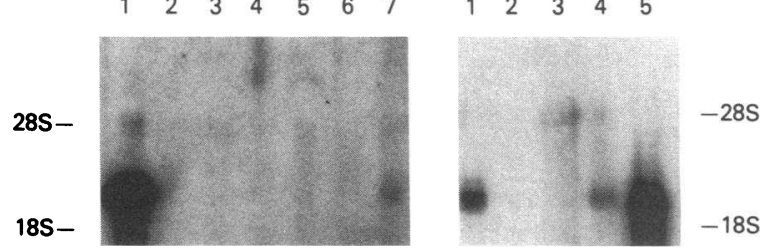

Figure 4. Northern blot analysis of cga expression in colon adenocarcinomas. (A) $10 \mu \mathrm{g}$ of total RNA extracted from a pheochromocytoma tumor specimen (lane 1 ) and $30 \mu \mathrm{g}$ of total RNA extracted from colon adenocarcinoma tumor specimens (lanes 2-7) were analyzed for cga expression by Northern blotting. (B) $10 \mu \mathrm{g}$ of total RNA extracted from an oat cell lung carcinoma cell line (lane 1), a lung adenocarcinoma cell line (lane 2), colon adenocarcinoma cell lines (lanes 3-4), and gastrointestinal carcinoid tumor (lane 5) were analyzed as in $\mathbf{A}$.

colon adenocarcinomas by routine histopathologic criteria. Because colonic mucosa is normally populated with neuroendocrine cells, it seems reasonable that some subsets of colon adenocarcinomas might have neuroendocrine features. Indeed, carcinoid tumors of the colon are known to be of neuroendocrine origin, but these differ histologically and biologically from adenocarcinoma of the colon (18). In addition, small cell undifferentiated carcinoma of the rectosigmoid colon is a neuroendocrine tumor occurring in less than $1 \%$ of primary rectosigmoid malignancies (19). The colon adenocarcinomas that expressed cga had none of the light microscopic or immunohistochemical evidence of neuroendocrine differentiation that has been reported for small cell cancers of the colonic mucosa (19). However, studies aimed at identifying more subtle evidence of neuroendocrine differentiation, such as the presence of dense core grandules or 1-dopa decarboxylase activity in the colon tumors expressing cga, will be of interest.
The colon cell line that expressed cga was derived from a patient who was presented with typical adenocarcinoma but relapsed with an anaplastic tumor from which the cell line was established. This cell line has dense core granules by electron microscopy and expressed low levels of 1-dopa decarboxylase (unpublished observations). These data, coupled with the in situ data shown in Fig. 5, suggest that this patient relapsed with a clone of tumor cells arising from a cell that had differentiated along a neuroendocrine lineage.

We also examined the Colo 320 colon carcinoma cell line which is of disputed epithelial-neuroectodermal origin (20). This cell line does not express cga by Northern blot analysis nor does it contain neurosecretory granules (data not shown). These data suggest that Colo 320 is not a neuroendocrine tumor cell line.

Our analysis of malignant tissues for the expression of cga RNA demonstrates the potential for the application of recombinant DNA technology to the classification of tumors. Our data define a neuroendocrine feature in a subgroup of colon adenocarcinomas that are distinguishable from carcinoid tumors of the colon and from undifferentiated small cell colon carcinomas. Our finding that some colon adenocarcinomas express cga, a very specific marker of neuroendocrine differentiation, is the first observation made using molecular techniques that suggests lineage relationships among tumors that have not been demonstrated to be related by other techniques.

Preliminary data from our laboratory indicate that both Northern blot analysis and in situ hybridization can be more sensitive than immunohistochemical analysis of gene expression (data not shown). In the specific case of cga, however, where both the mRNA and protein are expressed at high levels and an antibody is available (4), each of the techniques have specific advantages that can be exploited. For example, while immunohistochemistry can be performed more quickly than in situ hybridization, the latter technique allows a more quantitative determination of the levels of gene expression within a given cell. In this regard, the use of in situ hybridization to
Figure 5. In situ hybridization analysis of cga expression in the human colon adenocarcinoma cell line H-716. Log phase H-716 monolayer cells were prepared by cytospin onto slides and analyzed as described in Methods. 
analyze fixed specimens of human tumors should allow determination of the precise distribution of cga expression within a given tumor specimen.

There currently exist many molecular probes for which no antibody is available, and in this situation a molecular approach to tumor classification will clearly expand the armamentarium of pathologists. Previous studies examining $N$-myc amplification in neuroblastoma (21-23), neu amplification in breast carcinoma (24), and immunoglobulin gene rearrangement in leukemia-lymphoma (25-29) have also suggested that the molecular genetic classification of human tumors will be of clinical significance. Although more clinical studies of colonic adenocarcinomas will be required, our results suggest that the measurement of cga mRNA may prove to be a useful tool by which biologically distinct subsets of tumors that may arise during normal colonic mucosal maturation may be recognized.

\section{References}

1. Blaschko, J., R. S. Comline, F. H. Schneider, M. Silver, and A. D. Smith. 1967. Secretion of a chromaffin granule protein, chromogranin, from the adrenal gland after splanchnic stimulation. Nature (Lond.). 215:58-59.

2. Gorr, S. U., R. Kumarasamy, W. L. Dean, D. V. Cohn. 1987. New suggestions for the physiological role of secretory protein I. Bone Miner. 2:251-255.

3. Lloyd, R. V., and B. S. Wilson. 1983. Specific endocrine tissue marker defined by a monoclonal antibody. Science (Wash. DC). 222:628-630.

4. Wilson, B. S., and R. V. Lloyd. 1984. Detection of chromogranin in neuroendocrine cells with a monoclonal antibody. Am. J. Hum. Genet. 115:458-468.

5. DeStephano, D. B., R. V. Lloyd, A. M. Pike, and B. S. Wilson. 1984. Pituitary adenomas: an immunohistochemical study of hormone production and chromogranin localization. Am. J. Hum. Genet. 116:464-472.

6. Lloyd, R. V., T. Mervak, K. Schmidt, T. F. Warner, and B. S. Wilson. 1984. Immunohistochemical detection of chromogranin and neuron-specific enolase in pancreatic endocrine neoplasms. $\mathrm{Am}$. J. Hum. Genet. 8:607-614.

7. O'Connor, D. T., D. Burton, and L. J. Deftos. 1983. Immunoreactive human chromogranin $\mathrm{A}$ in diverse polypeptide hormone producing human tumors and normal endocrine tissues. J. Clin. Invest. 57:1084-1086.

8. O'Connor, D. T., and L. J. Deftos. 1986. Secretion of chromogranin A by peptide-producing endocrine neoplasms. N. Engl. J. Med. 314:1145-1151.

9. Sobol, R. E., D. T. O'Connor, J. Addison, K. Suchocki, I. Royston, and L. J. Deftos. 1986. Elevated serum chromogranin A concentrations in small-cell lung carcinoma. Ann. Intern. Med. 105:698-700.

10. Chirgwin, J. M., A. E. Przybyla, R. J. MacDonald, and W. J. Rutter. 1979. Isolation of biologically active ribonucleic acid from sources enriched in ribonuclease. Biochemistry. 18:5294-5299.

11. Helman, L. J., C. J. Thiele, W. M. Linehan, B. D. Nelkin, S. B. Baylin, and M. A. Israel. 1987. Molecular markers of neuroendocrine development and evidence of environmental regulation. Proc. Natl. Acad. Sci. USA. 84:2336-2339.

12. Cleveland, D. W., M. A. Lopata, R. J. MacDonald, N. J. Cowan, W. J. Rutter, and M. W. Kirschner. 1980. Number and evolutionary conservation of alpha- and beta-tubulin and cytoplasmic betaand gamma-actin genes using specific cloned cDNA probes. Cell. 20:95-105.

13. Folks, T. M., D. Powell, M. Lightfoote, S. Koenig, A. Fauci, S.
Benn, A. Rabson, D. Daugherty, H. E. Gendelman, M. D. Hoggan, S. Venkatesan, and M. A. Martin. 1986. Biological and biochemical characterization of a cloned leu 3-cell surviving with the acquired immune deficiency syndrome retrovirus. J. Exp. Med. 164:280-290.

14. Gendelman, H. E., S. E. Koenig, A. Adsamit, and S. Venkatesan. 1986. In situ hybridization for detection of viral nucleic acid in cell cultures and tissues. In situ hybridization in Brain. G. R. Uhl, editor, Plenum Publishing Corporation, New York. 203-223.

15. Maples, J. A. 1985. A method for the covalent attachment of cells to glass slides for use in immunohistochemical assays. Am. J. Hum. Genet. 83:356-363.

16. Hayashi, S., I. C. Gillay, A. D. Delaney, and G. M. Tener. 1978. Acetylation of chromosome squashes of Drosophila melanogaster decreases the background in autoradiographs from hybridization with ${ }^{125}$ I-labeled RNA. J. Histochem. Cytochem. 26:677-679.

17. Park, J. G, H. K. Oie, P. H. Sugarbaker, J. G. Henslee, T.-R. Chen, B. E. Johnson, and A. Gazdar. 1987. Characteristics of cell lines established from human colorectal carcinoma. Cancer Res. 47:67106718.

18. Moertel, C. G. 1983. Treatment of the carcinoid tumor and the malignant carcinoid syndrome. J. Clin. Invest. 1:727-740.

19. Schwartz, A. M., and J. M. Orenstein. 1985. Small-cell undifferentiated carcinoma of the rectosigmoid colon. Arch. Pathol. Lab. Med. 109:629-632.

20. Quinn, L. A., G. E. Moore, R. T. Morgan, and L. K. Woods. 1979. Cell lines from human colon carcinoma with unusual cell products, double minutes, and homogeneously staining regions. Cancer Res. 39:4914-4924.

21. Brodeur, G. M., R. C. Seeger, and M. Schwab. 1984. Amplifcation of $N$-myc in untreated human neuroblastomas correlates with advanced disease stage. Science (Wash. DC). 224:1121-1124.

22. Schwab, M., J. Ellison, and M. Busch. 1984. Enhanced expression of the human gene $N$-myc consequent to amplification of DNA may contribute to malignant progression of neuroblastoma. Proc. Natl. Acad. Sci. USA. 8:4940-4944.

23. Seeger, R. C., G. M. Brodeur, H. Sath, A. Dalton, S. E. Siegel, K. Y. Wong, and D. Hammond. 1985. Association of multiple copies of the $N$-myc oncogene with rapid progression of neuroblastoma. $N$. Engl. J. Med. 313:1111-1116.

24. Slamon, D. J., G. M. Clark, S. G. Wong, W. J. Levin, A. Ullich, and W. L. McGuire. 1987. Human breast cancer: correlation of relapse and survival with amplification of the HER-2/neu oncogene. Science (Wash. DC). 235:177-182.

25. Korsmeyer, S. J., P. A. Hieter, J. V. Ravetch, D. G. Poplack, T. A. Waldmann, and P. Leder. 1981. Developmental hierarchy of immunoglobulin gene rearrangements in human leukemic pre-B cells. Proc. Natl. Acad. Sci. USA. 78:7096-7100.

26. Korsmeyer, S. J., A. Arnold, A. Bakhshi, J. V. Ravetch, U. Siebenlist, P. A. Hieter, S. O. Sharrow, T. W. LeBien, J. H. Kersey, D. G. Poplack, P. Leder, and T. A. Waldmann. 1983. Immunoglobulin gene rearrangement and cell surface antigen expression in acute lymphocytic leukemias of $\mathrm{T}$ cell and B cell precursor origins. J. Clin. Invest. 71:301-313.

27. Nadler, L. M., S. J. Korsmeyer, K. C. Anderson, A. W. Boyd, B. Slaughenhoupt, E. Park, J. Jenson, F. Coral, R. J. Mayer, S. E. Sallan, J. Ritz, and S. F. Schlossman. 1984. B-cell origin of non-T cell acute lumphoblastic leukemia: a model for discrete stages of neoplastic and normal pre-B cell differentiation. J. Clin. Invest. 74:332-340.

28. Bakhshi, A., J. P. Jensen, P. A. Goldman, J. J. Wright, O. W. McBride, A. L. Epstein, and S. J. Korsmeyer. 1985. Cloning the chromosomal breakpoint of $t(14 ; 18)$ human lymphomas: clustering around $\mathrm{JH}$ on chromosome 14 and near a transcriptional unit on 18. Cell. 41:889-906.

29. Tsujimoto, Y., J. Gorham, J. Cossman, E. Jaffe, and C. M. Croce. 1985 . The $5(14 ; 18)$ chromosomal translocations involved in B-cell neoplasms result from mistakes in VDJ joining. Science (Wash. DC). 229:1390-1393. 